\title{
Performance of layer-by-layer (LbL) polyelectrolyte forward osmosis membrane for humic acid removal and reverse solute diffusion
}

\author{
Suriani Husaini, Mazrul Nizam Abu Seman
}

Faculty of Chemical \& Natural Resources Engineering, Universiti Malaysia Pahang, 26300 Gambang, Pahang, Malaysia. Article Info: Submitted on March 20, 2017, Accepted on June 20, 2017.

\begin{abstract}
Recent study claimed that forward osmosis (FO) process could handle the fouling problem due it driven force based on natural osmotic pressure. However, researchers observed that FO membrane had problem with reverse solute diffusion (RSD) of draw solution. Therefore, FO membrane properties must be improved either physically or chemically in order to overcome this problem. Among all, surface modification approach has been acknowledged as a best technique to alter the membrane properties without significantly change the bulk membrane properties. In this study, polyelectrolyte FO membrane has been produced through Layer by Layer (LbL) deposition method by using Poly (diallyl-dimethylammoniumchloride), PDADMAC and Poly (sodium 4-styrenesulfonate), PSS as an active monomers. Humic acid (HA) as part of Natural Organic Matter constituents was used as the feed solution and $\mathrm{NaCl}$ as a draw solution. The chemical structure and morphology of the $\mathrm{FO}$ membrane were characterized by FTIR and FESEM, respectively. From this study, the highest water flux and humic acid rejection were achieved at $2.5 \mathrm{M}$ of draw solution with value of $2.56 \mathrm{~L} / \mathrm{m}^{2} . \mathrm{h}$ and $99 \%$, respectively. In general, the water flux increases as the concentration of draw solutions were increased. However, it was observed that reverse salt diffusion (RSD) become worse at higher concentration of draw solution.
\end{abstract}

Keywords: Layer by Layer (LbL); Forward osmosis; Reverse salt diffusion (RSD).

\section{Introduction}

In forward osmosis (FO) membrane, the process utilizes an osmotic pressure gradient to extract water across a semi-permeable membrane from lower osmotic pressure of a feed solution to a draw solution. Due to this concentration gradient, FO does not require an external pressure and it is believed to deliver a lower fouling potential when the membrane active rejection layer having a contact with the foulantcontaining feed solution. In recent years, FO has been widely implemented in various sectors including desalination ${ }^{1,2,3}$, wastewater treatment ${ }^{4}$ and even in the food processing ${ }^{3}$.Not only that, research advances for the development high performance FO membrane has received much attention lately. According to Archilli et al., ${ }^{5} \mathrm{FO}$ tend to have low fouling despite the complicated mechanism involved. FO process normally depends on the properties of draw solution, membrane properties and other parameters. Membrane properties become one of the interesting subjects among researchers. Surface modifications seem to be the easy way to change the membrane properties without changing the overall membrane bulk properties. One of the surface modification methods is by Layer-by-Layer (LbL) approach. Ng. et al., ${ }^{6}$ have developed polyelectrolyte nanofiltration (NF) membrane by LbL approach and it was found that the membrane exhibited excellent performance towards desalination process. To the best of our knowledge, no one has applied LbL approach in FO membrane development for natural organic matter (NOM; i.e. humic acid) removal. The objective of the paper is to develop FO membrane by LbL method and investigate its performance towards humic acid removal and reverse solute diffusion.

\section{Materials and Methods}

\section{Chemicals}

$\mathrm{NaCl}$ (Fisherci, 95\% purity) solutions with different concentrations $(0.5 \mathrm{M}-2.5 \mathrm{M})$ were selected as draw solution. Diluted humic acid (HA) (Fluka) solution with concentration of $15 \mathrm{mg} / \mathrm{L}$ is used as the feed solution. Poly (diallyl-dimethylammoniumchloride) (PDADMAC, $\mathrm{M}_{\mathrm{w}}=100$ 000, 35 wt. $\%$ in $\mathrm{H}_{2} \mathrm{O}$ and Polysodium-4-styrenesulfoate (PSS, $\quad \mathrm{M}_{\mathrm{w}}=70000,30$ wt.\% in $\mathrm{H}_{2} \mathrm{O}$ ) were obtained from Sigma Aldrich which used as the respective polycation and polyanion for LbL assembly.

Layer by layer (LbL) membrane preparation UF substrate (UFPES50, Amfor, China) was stored in deionized water overnight to remove protective layer/impurities. Firstly, the porous UF substrate was 


\section{Chemical Engineering Research Bulletin 19(2017) 75-79}

immersed in PDADMAC (polycation solution) for 15 min. Then, it was taken out and rinsed with deionized water for $3 \mathrm{~min}$. Then followed by immersing in PSS solution for another $15 \mathrm{~min}$. After that, the membrane was rinsed with ultra-pure water for $3 \mathrm{~min}$. This step will give a complete one bilayer of self-assembly membrane. This complete step was repeated similarly until the 5 bilayers were achieved.

\section{Forward osmosis (FO) experiment}

The $15 \mathrm{mg} / \mathrm{L}$ of humic acid solution and the sodium chloride $(\mathrm{NaCl})$ in the range of $0.5-2.5 \mathrm{M}$ concentration solution were used as feed and draw solution, respectively. The feed solution containing humic acid solution is placed on the electric balance to record the mass changes in time interval of 5 minutes for 1 hour. All the measurements were taken at room temperature and atmospheric pressure. The water flux, $J_{w}$ for each draw solution concentration is measured by following equation:

$$
J_{w}=\frac{\Delta V}{A \times \Delta t}
$$

Where $V$ is the volume of collected permeates, $A$ is an effective area of the membrane and $\Delta t$ is time taken for complete FO experiment.

For humic acid rejection $(R)$, the color absorption of both draw and feed solution were analyzed at $256 \mathrm{~nm}$ wavelength by using UV-vis spectrometer. Then, the humic acid concentration could be obtained from the standard curve.

$$
\mathrm{R}=\left(1-\frac{C_{a}}{C_{b}}\right) \times 100 \%
$$

$C_{a}$ and $C_{b}$ is the concentration of humic acid in the draw solution and the feed solution, respectively.

For reverse salt diffusion (RSD) determination, the above procedure was repeated with the same range of draw solution concentrations but now pure water was used as feed replacing the humic acid. The reverse salt diffusion $\mathrm{J}_{\mathrm{s}}$ was determined from the feed conductivity changes over the predetermined time (1 hour) by using the following equation:

$$
J_{s}=\frac{\Delta\left(C_{t} \times V_{t}\right)}{A \times \Delta t}
$$

where, $C_{t}$ is $\mathrm{NaCl}$ concentration in feed solution and $V_{t}$ is the volume at the end of FO test, $\Delta t$ is time taken in hours and $A$ is the effective area of the membrane.

\section{Results and Discussion}

\section{Membrane characterization}

Change in chemical structure during the modification process was confirmed by FTIR. Figure 1 shows the FTIR spectrum for both unmodified and modified UF membranes with PSS and PDADMAC. As the chemical reaction progressed, there was additional peak at $1035 \mathrm{~cm}^{-1}$ (indicated by the arrow in Figure 1) which attributed to both the sulfonate stretching of PSS and the C-N stretching of PDADMAC ${ }^{7}$. This shows that the polyelectrolyte layers of PSS/PDADMAC were succesfully coated on the UF microporous support layer after LbL modification step.

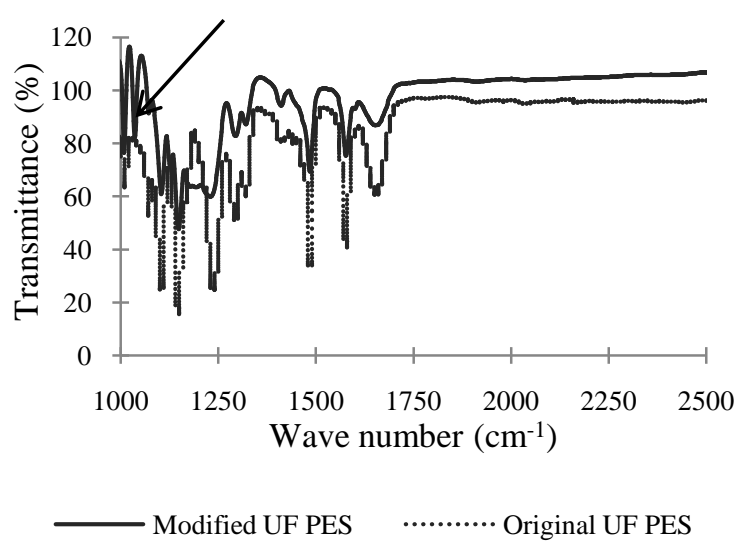

Figure 1: Graph of FTIR for modified and unmodified membrane.

A FESEM technique was applied to examine the LbL membrane morphology. Figure 2(a) shows the top surface of membrane where one can see the it has smooth surface. Smooth surface is believed could reduce fouling problem.Higher degree of membrane fouling is normally related to membrane with rougher surfaces especially when the size of the molecules and the relative scale of the roughness are similar ${ }^{8,9}$.Crosssectional of 5-bilayers PDADMAC/PSS with $280 \mathrm{~nm}$ thickness is displayed in Figure 2(b). As observed under FESEM,the new formed layer has denser structure compared to the bottom part. In this research, the top dense layer of polyelectrolyte membrane will face the feed solution whereas the bottom layer contact with draw solution. The dense film on the top surface of modified membrane will determine the performance of the FO membrane in term of water flux, humic acid rejection and reverse salt leakage. 


\section{Chemical Engineering Research Bulletin 19(2017) 75-79}
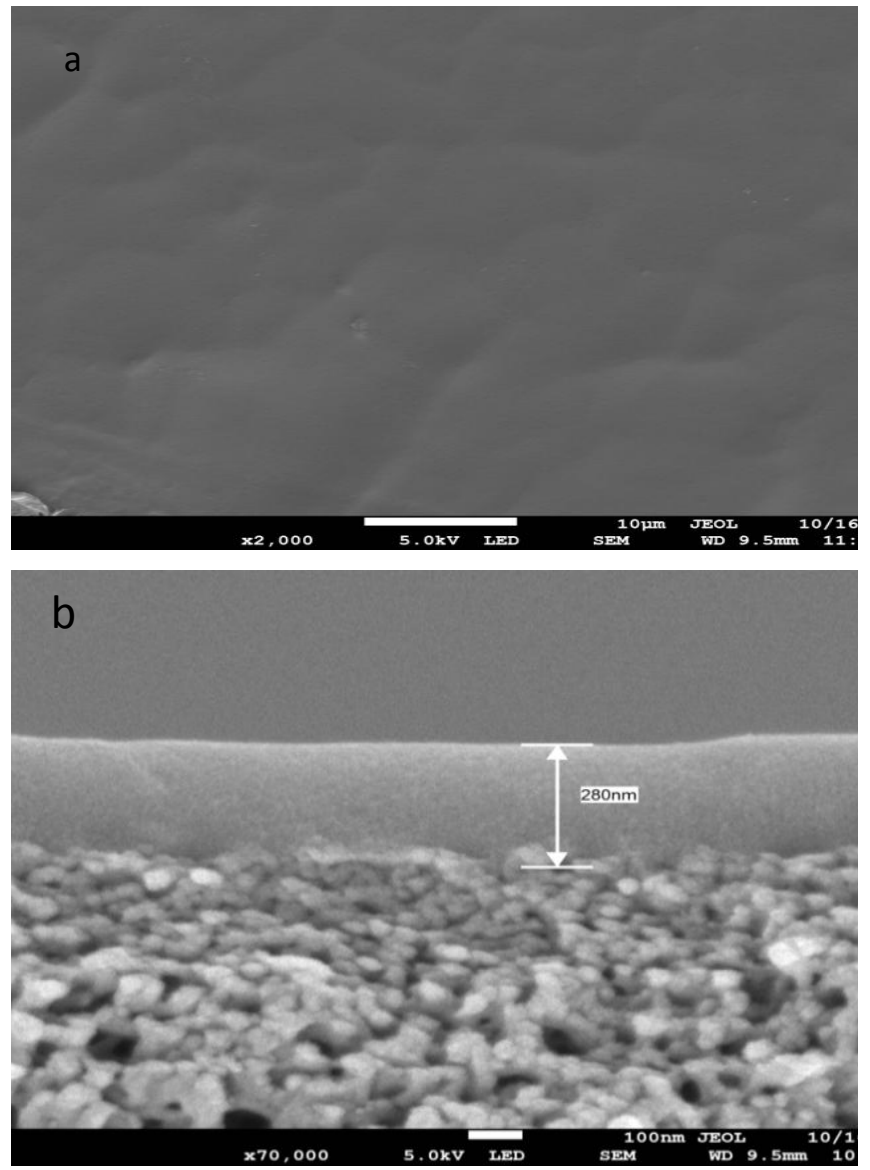

Figure 2: FESEM image of PDADMAC/PSS FO membrane morphology (a) top surface (b) Cross section of 5-bilayers of with $280 \mathrm{~nm}$ thickness.

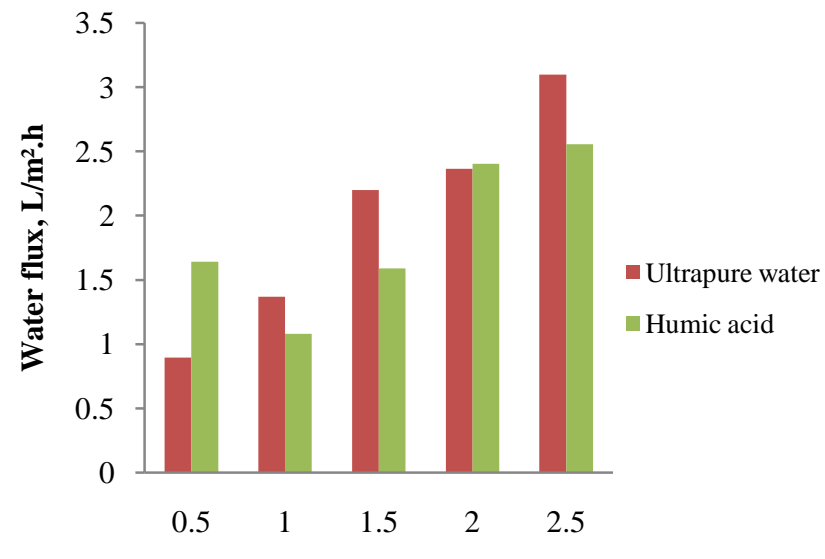

Draw solution concentration, $M$

Figure 3: Water Flux for difference feed solutions versus Draw solution concentration.

\section{Membrane performance}

Figure 3 shows water flux for polyelectrolyte FO membrane by using two different feed (ultrapure water and humic acid solution). Based on the graph as shown in Figure 4, in general it can be seen that the trend of water flux increase with the increase of draw solution concentration (i.e. sodium chloride, $\mathrm{NaCl}$ ). When pure water was used as feed, the highest water flux (3.10 $\mathrm{LMH}$ ) was achieved when using $2.5 \mathrm{M}$ concentration of $\mathrm{NaCl}$ while humic acid as feed solution exhibited a lower permeate flux $(2.55 \mathrm{LMH})$ at the same draw solution concentration. It is due to the fact that, the humic acid solute may accumulate at the membrane surface leading to concentration polarization effect, hence generate a lower water flux.

Furthermore, when the osmotic pressures increase, more water will draw from the feed solution to the draw solution. The difference in concentration between the feed and draw solution also brings significant effect on the water diffusion from the feed solution to draw solution ${ }^{2}$. When the draw solution concentration increase, the difference in concentration between the humic acid solutions and $\mathrm{NaCl}$ solution increase. Hence the water flux will also increase. This phenomenon occurs because of the driving force and the difference of osmotic pressure ${ }^{10}$. Figure 4 shows effect of draw solution concentration on humic acid rejection and it was observed that the removal of HA is quite high in the range of $96-99 \%$ and the maximum removal was achieved at the highest draw solution concentration $(2.5 \mathrm{M})$. This indicate the fabricated polyelectrolyte FO membrane in this study is capable to remove natural organic matter efficiently.

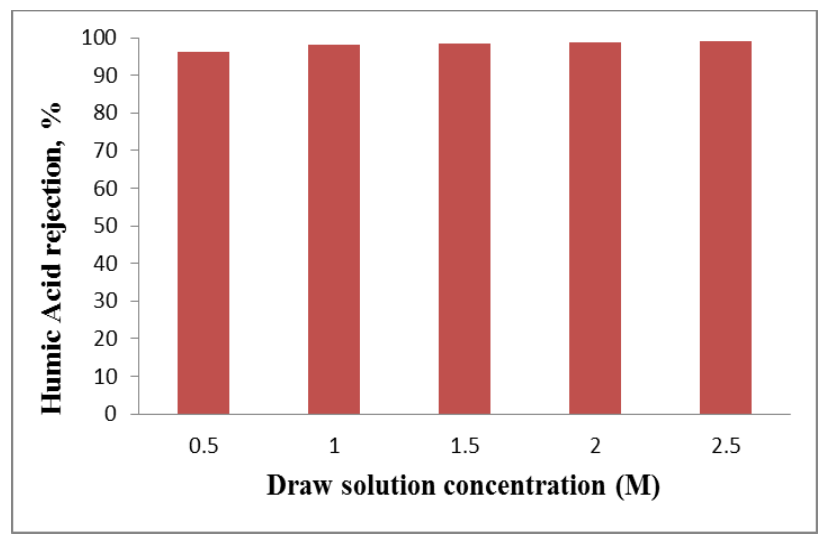

Figure 4: Graph of humic acid rejection against draw solution.

Even the fabricated FO membrane exhibited good performance in term of high flux and high HA removal, reverse solute diffusion (RSD) is one of the drawbacks of FO process. For this reason, RSD was further investigated in term of reverse salt flux $\left(\mathrm{g} / \mathrm{m}^{2} \mathrm{~h}\right)$ and the results were presented in Figure 5. Figure 5 shows the effect of salt concentrations on the reverse salt flux where reverse salt flux increase with increasing the draw solution concentration. When the $\mathrm{NaCl}$ concentration is $0.5 \mathrm{M}$, the reverse salt flux value 


\section{Chemical Engineering Research Bulletin 19(2017) 75-79}

is $0.0011 \mathrm{~g} / \mathrm{m}^{2} . \mathrm{h}$ while $2.5 \mathrm{M}$ of $\mathrm{NaCl}$ concentration the reverse salt flux become $0.0296 \mathrm{~g} / \mathrm{m}^{2} \mathrm{~h}$. Higher draw solution concentration contribute to higher reverse salt flux. This reverse salt flux occurs due to a low molecular weight of $\mathrm{NaCl}$ and low viscosity making small solute of $\mathrm{NaCl}$ can easily pass through the pores channel along the support layer and the active layer to diffuse into the feed solution. The diffusion of draw solution solute into the feed site is due to the concentration gradient between two sides. The reverse salt flux would decrease the water flux in the FO system as the draw solution is continously losing its solute due to migration of draw solute $(\mathrm{NaCl})$ into the feed site, hence reducing osmotic pressure and indirectly reducing water permeate flux as well.

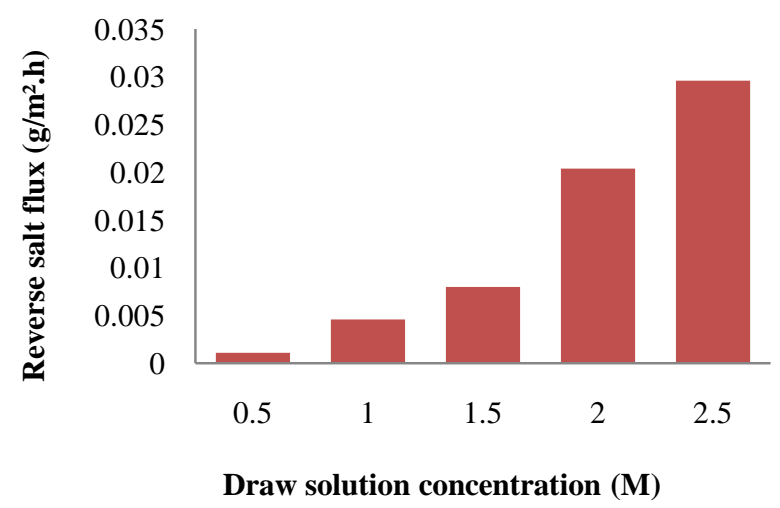

Figure 5: Graph of reverse salt flux against salt concentration in feed solution.

\section{Conclusion}

Based on the research conducted, polyelectrolyte membrane produced by LbL method improved FO membrane performance with enhancement in water permeability and lower reverse salt diffusion. A high water flux $(\mathrm{Jw})$ was about $3.098 \mathrm{~L} / \mathrm{m} 2 \mathrm{~h}$ and very low salt flux (Js) when using $2.5 \mathrm{M}$ of $\mathrm{NaCl}$ as draw solution and ultra-pure water as feed solution. Moreover, with humic acid as feed solution, water flux of about $2.5571 \mathrm{~L} / \mathrm{m} 2 \mathrm{~h}$ was obtained. Therefore, water flux for ultra-pure water as feed solution was higher than humic acid solution. The humic acid rejection for polyelectrolyte membrane was very high which is almost $100 \%$ and it increase with the increasing of the draw solution concentration. In order to improve this research, more parameters such as number of layers, PDADMAC/PSS concentration used for LbL deposition can be done to determine the best parameter to produce a higher efficiency polyelectrolyte FO membrane.

\section{Acknowledgement}

Support from the Universiti Malaysia Pahang, Malaysia and financial aid from RDU1603123 are gratefully acknowledged.

\section{References}

1. J.R. McCutcheon, R.L. McGinnis and M. Elimelech, "A novel ammonia-carbon dioxide forward (direct) osmosis desalination process," Desalination, vol. 174, pp.1-11, 2005.

2. S. Zhao, L. Zou and D. Mulcahy, "Brackish water desalination by a hybrid forward osmosisnanofiltration system using divalent draw solute," Desalination, vol. 284, pp.175-181, 2012.

3. T.Y. Cath, A.E. Childress and M. Elimelech, "Forward osmosis: principles, applications, and recent developments," Journal of Membrane Science, vol. 281, pp.70-87, 2006.

4. S. Zhao, L. Zou, C.Y. Tang and D. Mulcahy, "Recent developments in forward osmosis: opportunities and challenges," Journal of Membrane Science, vol. 396, pp.1-21, 2012.

5. A. Archilli, T.Y. Cath, E.A. Marchand and A.E. Childress, "The forward osmosis membrane bioreactor: A low fouling alternatives to MBR processes," Desalination, vol. 239, pp.10-21, 2009.

6. L.Y. Ng, A.W. Mohammad, C.Y. Ng, C.P. Leo and R. Rohani, "Development of nanofiltration membrane with high salt selectivity and performance stability using polyelectrolyte multilayers," Desalination, vol. 351, pp. 19-26, 2014.

7. T. Laakso, M. Kallioinen, A. Pihlajamäki, M. Mänttäri and J.E. Wong, "Polyelectrolyte multilayer coated ultrafiltration membranes for wood extract fractionation," Separation and Purification Technology, vol. 156, pp. 772-779, 2015.

8. M.N. Abu Seman, M. Khayet and N. Hilal, "Comparison of two different UV-grafted nanofiltration membranes prepared for reduction of humic acid fouling using acrylic acid and Nvinylpyrrolidon," Desalination, vol. 287, pp. 1929, 2012.

9. M.N. Abu Seman, M. Khayet and N. Hilal, "Development of antifouling properties and performance of nanofiltration membranes modified by interfacial polymerization," Desalination, vol. 273, pp. 36-47, 2011.

10. M. Xie, L.D. Nghiem, W.E. Price and M. Elimelech, "Impact of humic acid fouling on membrane performance and transport of pharmaceutically active compounds in forward osmosis," Journal of Water Research, vol.47, pp. 4567-4575, 2013. 
Chemical Engineering Research Bulletin 19(2017) 75-79

\section{Available online at http://www.banglajol.info/index.php/CERB}

